\title{
Afetos e Representações Sociais: Contribuições de um Diálogo Transdisciplinar ${ }^{1}$
}

\author{
Carolina Fernandes Pombo-de-Barros \\ Escola Nacional de Saúde Pública Sergio Arouca - ENSP / FIOCRUZ \\ Angela Maria Silva Arruda \\ Universidade Federal do Rio de Janeiro
}

\begin{abstract}
RESUMO - Este texto é resultado de uma pesquisa teórica cujos objetivos foram: explorar a afinidade entre a Teoria do Desenvolvimento Emocional, de Winnicott, e a Teoria das Representações Sociais, de Moscovici, e indicar o papel da afetividade na construção de representações sociais. Para dar sustentação ao diálogo das duas teorias, o texto aborda considerações de diferentes autores que se debruçaram sobre os processos de conhecer, perceber e interagir, e que defendem a complexidade dos fenômenos sociais e cognitivos e a necessidade de um paradigma transdisciplinar para investigá-los. Analisa, na conclusão, a presença do medo e da solidariedade nos resultados da pesquisa de Sandra Jovchelovitch sobre as representações sociais e a esfera pública no Brasil.
\end{abstract}

Palavras-chave: representações sociais; desenvolvimento emocional; transdisciplinaridade.

\section{Affection and Social Representations: Contributions of a Transdisciplinary Dialogue}

\begin{abstract}
This text is a result of a theoretical research with two goals: to explore common points between the Emotional Development Theory by Winnicott and the Social Representations Theory by Moscovici, and to indicate the role of affection in the construction of social representations. To sustain the dialogue between the two theories, this text approaches perspectives from different authors who have looked into the processes of knowledge, perception and interaction, and who have defended the complexity of the social and cognitive phenomena as well as the need of a transdisciplinary paradigm to investigate them. It is also analyzed, in the conclusion, the presence of fear and solidarity in the results of Sandra Jovchelovitch's research on social representations and the public sphere in Brazil.
\end{abstract}

Keywords: social representation; emotional development; transdisciplinarity.

Este artigo é fruto de uma pesquisa teórica com os objetivos de encontrar pontos de afinidade ente a Teoria das Representações Sociais (TRS), de Serge Moscovici, e a Teoria do Desenvolvimento Emocional (TDE), de Donnald Winnicott, e de apontar o papel da afetividade na construção de representações sociais. Para dar sustentação ao diálogo das duas teorias, o texto aborda considerações de diferentes autores que se debruçaram sobre os processos de conhecer, perceber e interagir, e que defendem a complexidade dos fenômenos sociais e cognitivos e a necessidade de um paradigma transdisciplinar para investigá-los. Esse percurso foi muito importante para o aprofundamento e compreensão das premissas epistemológicas das duas teorias, que caminham numa direção semelhante. Ao final, baseando-se nos pontos convergentes, o artigo analisa o papel dos afetos nas representações sociais da esfera pública no Brasil, pesquisadas por Jovchelovitch (2000).

Dois movimentos principais conduziram esta pesquisa: primeiro, a intenção de superar a dicotomia entre indivíduo e sociedade presente em algumas abordagens psicológicas, e segundo, contribuir para o debate sobre o papel dos afe-

1 Endereço para correspondência: Rua Humaitá, 68 Apto. 1006, Humaitá. Rio de Janeiro, RJ. CEP 22261-001. Telefone: 21-3268-4573 / 78462503.E-mail:carol_pombo@yahoo.com.br. tos na construção de representações sociais. A presença da dimensão afetiva nas pesquisas de representações sociais tem aumentado há cerca de 10 anos, aparecendo como pano de fundo até então, mesmo já tendo sido reconhecida nas definições básicas do fenômeno. Arruda (2007) aponta um debate, em curso, que enriquece esse meandro da teoria e que indica o desafio de explorar novos universos e recursos metodológicos para o acesso a esse aspecto das representações. Essa foi uma das razões para o recurso, neste trabalho, à teoria de Winnicott.

Winnicott (1988/1990), em seu projeto de desvendar alguns mistérios da "natureza humana", deixou para a psicologia e para a teoria psicanalítica uma herança singular, sendo reconhecido por seus trabalhos clínicos e suas considerações sobre o que chamou de "desenvolvimento emocional". Médico pediatra e psicanalista de adultos e crianças, não optou por uma psicanálise exclusivista nem por uma medicina puramente fisiológica. Acrescentou às suas observações médicas contribuições psicanalíticas e vice-versa, produzindo uma maneira inovadora de encarar a constituição do sujeito e a intervenção terapêutica, esforçando-se para manter uma visão transdisciplinar.

Sem notar, e talvez sem intencionar, Winnicott se inseria no movimento da crítica paradigmática, representada por pensadores de diferentes campos do conhecimento, que vem 
crescendo desde a segunda metade do século XX. Morin (1973/1975), defensor de uma revolução paradigmática, argumenta que esta é impulsionada pela necessidade da Ciência reconhecer suas limitações diante de novas descobertas que contrariam seus princípios básicos de ordem, separabilidade e razão. Ele denuncia os problemas que o isolamento e especialização das disciplinas podem causar, principalmente para o desenvolvimento das ciências humanas, e propõe a transdisciplinaridade, a visão sistêmica e a visão em espiral (retroalimentação) da relação do homem com o meio.

É nesse mesmo lugar de renovação do conhecimento que se posiciona a TRS. Moscovici (2000/2003) propôs que se considere a representação social como um processo que torna o conceito e a percepção intercambiáveis, que se engendram reciprocamente. As funções das representações sociais se desdobram em: construção do saber que orienta e justifica a ação, e elaboração de papéis e identidades sociais (Jodelet, 2001). Portanto, promovem uma aproximação de mão-dupla entre conceitos que a psicologia clássica opôs. É essa característica epistemológica que marca a teoria, localizada na interface entre a psicologia e a sociologia, inserida, portanto, no campo da psicossociologia. A interação entre os processos sociais e psíquicos, entre as experiências subjetivas e as percepções objetivas, no nível das condutas, dos agentes, e dos grupos, é um foco importante da psicossociologia. Esta pretende ser um campo de saber específico, porém não autônomo, pois se alimenta de fontes da psicologia e das ciências sociais (Maisonneuve, 1977).

Portanto, nesta pesquisa, a opção por articular as teorias desses dois autores - um psicanalista e outro psicólogo social - explica-se por um ponto em comum: o da interação. A TRS chama atenção para o lugar ativo do sujeito na construção dos significados coletivos, enfatizando um construtivismo psicossocial. A psicologia de Winnicott (1971/1975) aponta para o papel do social no desenvolvimento emocional dos sujeitos, encontrando na vida dos bebês fenômenos que já indicam a influência fundamental do ambiente na constituição psíquica. Enquanto se estuda uma e outra teoria, percebe-se que não há um limite claro entre o subjetivo e o real, entre o individual e o coletivo. A vida humana é própria de uma rede entrelaçada e inseparável do Eu com o Outro, e o indivíduo se constrói com o que essa rede lhe possibilita, modificando-se e modificando o ambiente do qual faz parte.

Por isso, já partimos da noção de que a dimensão afetiva está implicada na construção de representações sociais, e que para pesquisar esse fenômeno precisamos dialogar amplamente com abordagens psicológicas e psicanalíticas que focalizam a vida afetiva, mas não se fecham no "subjetivismo".

\section{Método e Premissas Epistemológicas}

Foram percorridas três etapas principais para este trabalho: a primeira, uma revisão bibliográfica na busca de um paradigma que superasse, principalmente, o princípio de separabilidade do positivismo moderno; a segunda, uma análise das premissas epistemológicas e dos principais conceitos das duas teorias, culminando em seus pontos convergentes; e a terceira, uma discussão do papel dos afetos na construção de representações sociais, analisando os resultados da pesquisa de Jovchelovitch (2000), "Representações sociais e esfera pública - a construção dos espaços públicos no Brasil”.

Assim, iniciamos com uma discussão que favorece o diálogo das teorias e previne o simples transporte dos conceitos de uma ao corpo da outra. Discutimos as contribuições de Morin (1973/1975), Berger e Luckmannn (1966/2007) e Varela (1998) para uma noção diferenciada das relações entre subjetividade e objetividade, indivíduo e meio social. Articulamos as premissas epistemológicas da TRS e da teoria winnicottiana pela lógica da retroalimentação, o que permitiu encontrar pontos significativos de convergência. Com isso, além das semelhanças, encontramos uma relação dinâmica entre o processo de desenvolvimento emocional e a construção de representações sociais. Nesse tópico, abordaremos as considerações das duas primeiras etapas da pesquisa.

As críticas de Morin (1999) produzem a ampliação do olhar sobre o homem e sua relação com o ambiente. $\mathrm{O}$ autor argumenta que a antropologia (a ciência do homem), em seus primórdios, desenvolveu-se com base em uma premissa antinaturalista, marcando o paradigma natureza x cultura. Essa cisão orientou o desenvolvimento das ciências e resultou numa visão de mundo segmentada em três estratos: Humanidades x Biologia x Física e Química. Suas observações sobre o desenvolvimento científico o levaram a reivindicar um novo paradigma que centraliza a noção de complexidade e transdisciplinaridade.

O olhar da complexidade é a constatação da constituição multidimensional dos homens e seus ambientes. Trata-se de considerar que elementos que costumávamos separar antagonicamente (como razão e corpo, cognição e emoção, natureza e cultura), participam de redes de interdependências e relações complexas. Essas redes se alimentam por cadeias retroativas, que produzem novas formas de vida. Para Morin (1999), a individualidade e as sociedades humanas são historicamente constituídas, pela lógica da complexidade, ao longo da filogênese.

A transdisciplinaridade é, assim, proposta como o paradigma científico que permite a melhor compreensão dessa multidimensionalidade. O objetivo é a articulação de diferentes teorias, com focos diferentes, que podem enriquecer seu corpo teórico mutuamente. Orientados pela visão da complexidade, os estudos transdisciplinares, que buscam articular teorias psicológicas com teorias sociais evitam a simples captura dos conceitos de uma pela outra.

Outro autor que desenvolveu uma nova teoria a partir das críticas à epistemologia e ontologia de teorias positivistas foi Varela (1998). Sua teoria já foi relacionada à TRS por Sancovischi (2007), a fim de dirimir mal entendidos sobre o conceito de representação usado por Moscovici. Partindo das falhas das máquinas da I. A. (Inteligência Artificial), no campo das ciências cognitivas, Varela (1998) propôs uma espécie de construcionismo que se diferencia do construtivismo piagetiano pela indeterminação dos processos de construção da realidade e da subjetividade. Sua proposta é a da "enação”, que significa dizer que a cognição é corporificada: são necessárias experiências sensoriais para a produção de conhecimento, e o próprio mundo que age sobre esse corpo é também modificado pelo sujeito cognoscente (Varela, 1998). Sua visão se assemelha à afirmação de Morin (1999) de que só é possível compreender a autonomia de um ser 
vivo situando-o em seu contexto de dependências múltiplas com seu meio-ambiente.

Com o conceito de autopoiese, Varela (1998) define que todos os organismos vivos estão adaptados aos contextos em que vivem e, portanto, estão em ato contínuo de conhecer o mundo. Viver é um processo cognitivo, é uma constante adaptação ao meio que é apreendido pelo sujeito. Este está em constante reorganização, como um sistema fechado, mas que responde às interferências do contexto (Varela, 1998). "A percepção é um processo ativo na produção de hipóteses, e não um simples espelho de um determinado ambiente" (Varela, 1998, p. 81).

Para Varela (1998), a percepção é criativa, é um processo de interpretação contínuo, que depende da ação e da história. Por isso, Varela critica o postulado representacional. Sua crítica se refere diretamente ao sentido forte da representação, que tem repercussões epistemológicas problemáticas. O sentido forte parte do pressuposto de que existe um mundo dado e que a nossa atividade cognitiva se limita a apreender isso que está dado. Mas o que chama de sentido fraco da representação aproxima-se do uso que a TRS faz do conceito (Sancovischi, 2007), que consiste em um uso semântico e pragmático. As representações sociais de Moscovici trabalham com a representação como interpretação e criação².

No campo da sociologia, surgiram abordagens construtivistas, que procuraram relativizar as dicotomias do positivismo, considerando a sociedade e os sujeitos em constante coprodução. Por isso, sua proposta é a de debruçar-se sobre um objeto considerando as múltiplas relações que o definem, especialmente as relações entre interações e estruturas sociais.

Corcuff (1995/2001) faz uma revisão das teorias construtivistas que surgiram desde os anos 1950 e as diferencia em quatro formas básicas, que vão desde as focadas nas estruturas sociais até aquelas mais radicais, que tentam eliminar as polarizações, como a sociologia discursiva. Uma das formas de construtivismo apontada por Corcuff é a que faz o percurso das interações às estruturas sociais, e nela ele insere o trabalho de Berger e Luckmann (1966/2007). Esses autores são, no âmbito da sociologia, os que mais se aproximam da TRS, porque destacam o processo de construção da realidade pelo conhecimento usado no dia a dia do homem comum. Eles consideram que o conhecimento é construído por meio de diferentes relações sociais institucionalizadas, das quais são legitimadas formas de pensar, perceber e viver. Assim, a sociedade é realidade objetiva que se impõe às pessoas, mas ao mesmo tempo é realidade subjetiva porque é interiorizada pelos sujeitos no processo de socialização. Essa interiorização não é uma apreensão simples, mas é criativa, produtora de sentidos nas interações face a face.

Apesar de diversos pesquisadores localizarem a TRS no campo do construtivismo, é importante salientar que a radicalização dessa abordagem ${ }^{3}$ pode chegar na "morte do sujeito", que significa diluir a subjetividade na linguagem

2 O uso que Moscovici faz do conceito de representações se baseia, principalmente, do diálogo que estabeleceu com a teoria de Durkheim, na tentativa de superar o que esse sociólogo denominava "representações coletivas" sob uma perspectiva positivista.

3 A radicalização do construtivismo pode ser identificada com o construcionismo social e a sociologia discursiva.
(Jovchelovitch, 2000). Se, por um lado, é importante nos afastarmos da noção dicotômica, que torna impossível uma ciência da subjetividade e ignora sua impregnação nos objetos, por outro lado, considerar o sujeito apenas como transitórias posições linguísticas não nos permite avançar. Essa concepção impede o reconhecimento das relações complexas da subjetividade com o corpo e com as estruturas sociais, que se referem à aceitação, por parte do pesquisador, da posição desconfortável do sujeito humano - inacabado, permanentemente em constituição. Jovchelovitch (2000) argumenta que tal posição é importante para entendermos as mediações entre os sujeitos, na dimensão simbólica.

Ele (o sujeito) não se define nem por dentro nem por fora. Excêntrico em seu modo mesmo de constituição, e sem condições de coincidir plenamente com aquilo que ele não é, o sujeito é condenado a buscar mediações. Outro, palavra e ação constituem - em delicada e intricada trama - estas mediações: com elas tentamos acalmar as lacunas que constituem o que somos. (Jovchelovitch, 2000, p.183)

A discussão traçada até aqui nos leva a evitar as dicotomias, mas não a eliminar os paradoxos, entendendo que nossos pólos de análise são intricados e repercutem um no outro. Subjetividade e objetividade são paradoxos, mas não extremos contrários, assim como individualidade e sociedade, emoção e cognição. Assim, é possível entender a inovação da representação social proposta pela TRS e também o interesse de Winnicott pelos paradoxos próprios da vida humana, considerando-os fundamentais em sua teoria. Por isso, não é interessante diluir o sujeito nem fixá-lo em modelos fechados, o que é mais produtivo é reconhecer sua complexidade e dialética com o ambiente. O sujeito é constituído em múltiplas dimensões e relações, sendo portanto, dinâmico, histórico e coprodutor da realidade. A subjetividade é formada pelas fronteiras habituais, relativamente estáveis, da individualidade, configuradas pelas racionalidades com as quais se percebe o mundo, institucionalizadas socialmente e transmitidas ao longo do desenvolvimento de cada um. Portanto, os processos de representar repercutem sobre o desenvolvimento emocional e este, em contrapartida, é criativo, contribuindo para a partilha de novos sentidos.

\section{Para Começo de Conversa: O Que Diz Cada Teoria}

O desenvolvimento da TRS fez parte de um projeto mais amplo de Moscovici pela construção de uma Psicologia Social do conhecimento. Sua ideia original era entender de que forma o conhecimento científico influencia a cultura e o pensamento do senso comum. Para ele, a psicologia social deve se ocupar das questões de uma sociedade pensante, do homem como sujeito que procura compreender, e não apenas comportar-se (Duveen, 2000/2003). A representação social aponta para o entrelaçamento entre o objeto representado e o sujeito que o representa. Ela é um conhecimento organizado mais elaborado, construído e legitimado socialmente, influenciado pela história e pelas práticas cotidianas, sobre um determinado objeto. Esse objeto é sempre social e está 
inserido em uma cultura, da mesma forma que os sujeitos que o representam só o fazem porque participam de uma sociedade e porque desenvolveram mecanismos cognitivos e afetivos próprios a essa forma de conhecimento (Moscovici, 2000/2003).

Sobre as principais premissas epistemológicas da TRS, lançamos mão dos eixos desenvolvidos por Arruda (2003) e do espaço de estudos das representações sociais, abordado por Jodelet (2001). O primeiro eixo a considerar é o da construção social da realidade, que se baseia em uma abordagem construtivista, que já foi explorada neste texto. O segundo e terceiro são diretamente decorrentes do anterior, a saber: a função primordial da comunicação no processo de constituição da realidade e o intercâmbio das formas de conhecimento para essa construção. Essa consideração diz respeito à polifasia cognitiva (Jovchelovitch, 2001). Ela denomina o fato de que se recorre a formas diversas de racionalidade na interpretação da realidade e que estas são incorporadas pelos atores de acordo com o contexto situacional, histórico e cultural.

Outro eixo importante colocado por Arruda (2003) é o da criatividade do sujeito cognoscente. Aqui é que se faz o corte mais significativo em relação às representações coletivas de Durkheim (1953/1974). Ele tinha uma visão centrada na coerção da sociedade sobre os indivíduos e na função normativa das representações coletivas, e Moscovici (1978) se interessou pelo uso que os homens fazem do conhecimento no cotidiano e por sua participação na produção de representações sociais. Assim, a TRS não concebe o sujeito como passivo diante dos ditames sociais. O sujeito é ativo, faz escolhas, combina e reinventa as imagens carregadas de representações, e recorre a estas para compreender as situações que o despertam, para tomar atitudes ou emitir opiniões.

O último eixo abordado por Arruda (2003) caracteriza as representações sociais como forma de conhecimento própria das sociedades complexas, multifacéticas, na era da informação e da velocidade das comunicações. Moscovici (1966/1978) as caracteriza como forma de conhecimento atual, bem diferente da cultivada no senso comum na Idade Média. Em nosso tempo, a ciência adquiriu uma legitimidade que ultrapassa os dogmas religiosos, ela se expande e interpenetra o cotidiano dos grupos sociais, ao mesmo tempo em que a multiplicidade de polos de poder possibilita a emergência de várias interpretações do real. Por isso, esse autor se interessou primeiramente pelas repercussões do conhecimento científico no conhecimento cotidiano. Ele se ocupou da construção de representações sociais que deem conta dos "novos" e exóticos conteúdos culturais e fenômenos sociais próprios do intenso contato entre diferentes culturas na contemporaneidade, a partir da incorporação de termos científicos no repertório do dia a dia.

As premissas da TRS permitem ver a complexidade da interface porosa sujeito-sociedade, pois o fenômeno de construção de representações sociais é próprio dessa zona de sombra complexa. Elas são elaboradas pelo sujeito para compreender o mundo, num processo criativo e prescritivo, pois contribuem para a identidade social, por meio das marcas que conferem aos grupos, e ao mesmo tempo, são dinâmicas, sujeitas a transformações resultantes das práticas cotidianas (Jodelet, 1988). Se Moscovici (2000/2003) considera a força prescritiva das representações como irresistível, também acentua que cada indivíduo repensa e reapresenta essas representações, para si mesmo e para o outro. Os símbolos e significados constituintes delas são manipulados, apropriados e investidos de interesses pessoais.

\section{É, pois, na fronteira entre o psicológico e o social, que se foca- liza a noção de representação social. Ela concerne, em primeiro lugar, a forma pela qual nós, sujeitos sociais, apreendemos os acontecimentos da vida corrente, os dados do nosso ambiente, as informações que ai circulam. (Jodelet, 1988, p. 7)}

Diante dessa complexidade, diferentes perspectivas de enfoque quanto às pesquisas em representações sociais são possíveis. Segundo Arruda (2003), o recurso a metodologias combinadas se torna frutífero por facilitar uma angulação variada do objeto, expondo mais da sua complexidade. Assim, Jodelet (2001) configurou um espaço de estudo multidimensional da teoria. Esse espaço de estudo é constituído basicamente de um esquema central, no qual as pesquisas convergem, que designa a relação sujeito - representação objeto, perpassado por outros elementos e relações. Jodelet (2001) descreve três ordens de problemáticas que conduzem as pesquisas, que são: a das condições de produção e circulação das representações, que se orienta para estudos da cultura, da linguagem e comunicação, ou da organização social, nos quais são geradas as representações; a dos processos e estados das representações, que resgata as formas de elaboração, a função e a eficácia delas, considerando os aspectos cognitivo-afetivos; e a do estatuto epistemológico da teoria, que estuda basicamente a relação entre ciência, realidade e representação social, o valor de verdade das representações. Apesar de serem territórios aparentemente autônomos, essas ordens são ao mesmo tempo interdependentes.

Já Winnicott (1971/1975) não apresenta de forma rigorosa as premissas que embasam sua teoria do desenvolvimento emocional, a não ser pela menção do paradigma do inconsciente freudiano, deixando, porém, clara, sua pretensão de contribuir com novos conceitos para a teoria psicanalítica. Ele fala do lugar de psicanalista, mas sem se restringir ao linguajar próprio desse circuito. Por isso, é considerado de um grupo heterogêneo dentre as diferentes vertentes psicanalíticas, como a estruturalista e a ortodoxa (Figueiredo, 1997). A citação seguinte esclarece o porquê dessa heterogeneidade:

Poucos psicanalistas foram tão longe quanto Winnicott na desconstrução das fronteiras entre interioridade e exterioridade, entre os aspectos internos do sujeito e a objetividade da realidade externa. Esta distinção de seu pensamento coloca sua teoria em diálogo com a de outros autores que, em outras áreas, compartilham da mesma inspiração inicial... (Bezerra Jr \& Ortega, 2007, p. 9)

Podemos extrair dos textos de Winnicott uma insistência em trazer para a psicanálise a intersubjetividade e a experiência cultural. Para ele, a experiência cultural não havia encontrado seu verdadeiro lugar na teoria mais utilizada pelos psicanalistas da época, apesar de ser fundamental para que o indivíduo consiga conviver com os paradoxos da vida. Ele atenta para o problema do paradoxo objetividade 
$x$ subjetividade, considerando-o inerente à experiência humana, e não somente como uma questão da ciência. Propõe uma visão alternativa que não privilegia nem um pólo nem outro, mas concilia os dois por meio da conceituação da área intermediária. $\mathrm{O}$ paradoxo entre dependência $x$ autonomia é também decorrente desse conflito entre o que é objetivamente percebido e subjetivamente concebido, e está na base do reconhecimento da alteridade. É a partir da experiência dos paradoxos que o selfé constituído, e o sujeito aprende a lidar com eles por meio dos fenômenos transicionais. Esses fenômenos são fundamentais para a criatividade e a vida social do sujeito (Winnicott, 1971/1975). Podemos dizer que Winnicott se ocupou principalmente da integração subjetiva por meio das relações do humano com o ambiente, não reduzindo o desenvolvimento emocional ao funcionamento de forças intrapsíquicas.

Assim, ele propôs que o indivíduo amadurecido experimenta uma região psíquica interna, uma região psíquica externa, e uma região intermediária (na qual emergem os afetos), por meio da qual pode lidar com as outras duas simultaneamente. De intermediária ele também nomeia a fase de transição da indiferenciação subjetiva para a integração do Eu, e conceitua que é a partir dos fenômenos transicionais que um bebê desenvolve a habilidade de reconhecer o outro e lidar com a realidade. Portanto, os fenômenos transicionais são: (a) experiências primitivas de possessão de objetos não-eu, quando o bebê está saindo da fase de dependência absoluta com a mãe. Na falta da fonte de sua satisfação, $o$ ato de chupar os dedos, por exemplo, a substitui afetivamente. Essa seria a primeira forma de simbolização da criança. Essa definição está relacionada ao paradoxo dependência $x$ autonomia; (b) experiências nas quais o sujeito sente-se parte de algo externo, conservando sua autenticidade, já na fase madura, quando o self já está integrado. A atividade do brincar criativo é, assim, um fenômeno transicional. O uso de um objeto transicional equivale, progressivamente, ao uso que o sujeito adulto faz da cultura, apropriando-se de seus elementos para afirmar sua potencialidade individual. Essa definição está mais próxima do paradoxo subjetividade $x$ objetividade.

É importante enfatizar que, como os paradoxos são inerentes à vida humana, a integração subjetiva é relativa, assim como a autonomia. As relações que o sujeito estabelece ao longo da vida constituem, em diferentes graus e aspectos, o que ele é, e isso é dinâmico. Assim, todo ser humano relativamente integrado possui a necessidade de se diferenciar em uma identidade própria, ao mesmo tempo em que, para isso, necessita da presença do outro. Para Winnicott (1945/1988), a criança só se sente livre para expressar sua espontaneidade depois de ter experimentado um ambiente estável e acolhedor, que receba sua criatividade. A criatividade tem a função de possibilitar essa autenticidade, partindo da apropriação daquilo que não faz parte do self, ou podemos dizer, daquilo que é objetivamente percebido. Por isso a cultura não provoca apenas a repressão, mas favorece a criatividade e a adesão a valores compartilhados. Portanto, o desenvolvimento da subjetividade individual está fortemente ligado ao meio social, à criatividade e à mediação dos afetos.

A criatividade é como uma força vital que, assim como a sexualidade e a agressividade, cresce ao longo de toda a vida do indivíduo. Um início bem sucedido da atividade imaginária e de simbolização proporciona o estabelecimento de um espaço potencial, uma espécie de confiança interna de poder expressar-se ao manipular objetos do espaço coletivo (Winnicott, 1971/1975). A tensão causada pela necessidade de relacionar a realidade externa com as experiências privadas é, em contrapartida, aliviada por este espaço. A escolha dos objetos e a forma como eles são usados estão ligadas aos afetos. A questão dos afetos, para a psicanálise, ainda é resolvida parcialmente por meio da relação da criança com a mãe e posteriormente com a família nuclear. Porém, a importância que Winnicott confere ao ambiente, em todo desenvolvimento emocional, nos incentiva a pensar nas interferências da cultura e dos símbolos sociais na afetividade.

Winnicott também olhava pela ótica do contraponto de saúde x doença. Influenciado pelos acontecimentos históricosociais de sua época (Pós-II Guerra Mundial), acreditava que a integração subjetiva é o resultado e ao mesmo tempo a força motivadora de uma sociedade saudável. A sociedade democrática seria consequência da saúde mental de seus membros e proporcionaria a integração para os demais, gerando um ciclo positivo, pois ela oferece a seus cidadãos a liberdade de expressar a criatividade (Winnicott, 1965/1993). Esta experiência autêntica de si mesmo, e de participação social, era para ele sinônimo de felicidade. Ainda assim, admitia que tais conclusões só eram possíveis baseadas na "atitude geral de nossa sociedade" e na "atmosfera filosófica na qual vivemos" (Winnicott, 1971/1975, p. 95). Portanto, ele não via a integração como prerrogativa de todo ser humano, mas como própria de certos modelos político-sociais, ainda que fizesse essa diferenciação pela ótica do normal x patológico.

Finalmente, devemos marcar certa visão transdisciplinar de Winnicott, quando, pensando sobre a natureza humana, deixou claro que a articulação de diferentes campos do saber é fundamental. Depois de considerar os objetos de pesquisa de diversos campos do conhecimento, Winnicott (1988/1990) finaliza com a seguinte afirmação:

\begin{abstract}
...e é necessário que possamos juntar numa única exposição complexa os comentários produzidos a partir de cada um desses postos de observação. Não é necessário adotarmos um método único e exclusivo para a descrição do ser humano. É bem mais lucrativo familiarizar-se com cada um dos métodos de abordagem conhecidos. (p. 25)
\end{abstract}

\section{Frutos do Diálogo: Pontos Convergentes}

O ponto de convergência mais importante que encontramos nesta pesquisa refere-se à postura epistemológica e ontológica de Moscovici e Winnicott no desenvolvimento de suas teorias. Para compreendê-la, lançamos mão de contribuições de críticas e teorias de outros autores, que se confrontam diretamente com conceitos e paradigmas tradicionais, como Varela e Morin.

O enfoque nas dicotomias, próprio de teorias psicológicas e sociais clássicas, é substituído pelo interesse nos fenômenos relacionais, paradoxais e intermediários. Tanto Winnicott quanto Moscovici não suspendem as noções de subjetividade e objetividade, mas conciliam os dois polos sem sobrepor um 
ao outro, e é isso que possibilita enxergar a dimensão afetiva. Moscovici segue essa orientação num contexto acadêmico de críticas ao paradigma positivista na psicologia social e de surgimento de abordagens construtivistas na sociologia. Winnicott não parece se opor necessariamente ao positivismo, mas busca o desenvolvimento de pontos "esquecidos" da teoria e do movimento psicanalítico contemporâneo. O desdobramento da postura epistemológica dos autores nos levou a identificar principalmente os seguintes pontos convergentes entre suas premissas: fluidez entre sujeito e meio / objeto, importância da função da criatividade, e abertura para transdisciplinaridade. Em seguida analisaremos esses pontos ao longo do desenvolvimento emocional e nos processos de construção de representações sociais.

Podemos partir da mediação básica da alteridade para a construção da integralidade do Eu psíquico. Este processo de integração é complexo, perpassado pelos fenômenos próprios do campo psicossociológico, como a comunicação e a modificação das estruturas mentais pela dinâmica interpessoal e grupal. Winnicott descreveu a família como um sistema de relações de interdependência que contribui para a integração subjetiva de cada um de seus membros (Winnicott, 1965/1993). O paradoxo de dependência x independência estabelece o sistema com suas características próprias, por meio de esforços coletivos e individuais. As trocas entre os indivíduos e as contribuições mútuas entre sujeito e sociedade são o que mantém vivo o sistema social, e ao mesmo tempo mantém viva a individualidade de cada um, retroalimentando adaptações e mudanças. Assim, a ameaça da desintegração do grupo social pode recair sobre a integração do próprio self, produzindo inclusive fenômenos novos.

O compromisso grupal é, portanto, fundamental para a manutenção da integração subjetiva, e a apropriação de representações sociais contribui para esse compromisso. Pesquisadores do desenvolvimento cognitivo infantil concluíram que a atividade representacional está ligada à apreensão cultural dos objetos e dos valores inerentes ao funcionamento social (Chombart de Lauwe \& Feuerhahn, 2001). A apropriação de representações sociais contribuem para a interiorização de experiências, práticas, modelos de condutas e pensamento, valorizados e transmitidos nos grupos sociais, com implicações afetivas e normativas (Jodelet, 2001). Na brincadeira, a criança tem a oportunidade de experimentar papéis sociais, de manipular símbolos que servem para a construção de uma identidade própria, e esses são vetores de representações sociais. Podemos dizer que a construção de representações sociais faz parte de um compromisso psicossocial, que mantém um certo equilíbrio entre os membros de um grupo, ao mesmo tempo em que contribuem para a organização do pensamento de cada sujeito. Para a configuração desse compromisso, a comunicação e a linguagem são fundamentais.

A transmissão das representações se dá por meio da comunicação interpessoal, institucional ou midiática (Jodelet, 2001). A própria linguagem é prática social, e as palavras são suporte de representações sociais (Harré, 2001). Portanto, como a comunicação interpessoal tem um papel significativo na aquisição da linguagem pela criança e na sua socialização, desde esse período ela já está cercada por representações sociais, e seu mundo se construirá também a partir delas. Segundo Brougère (2004), a infância é um momento privilegiado de apropriação de imagens e de representações. As imagens são elementos que condensam diferentes significados, desde muito cedo, dentro do universo perceptivo da criança, oferecendo a ela um amplo repertório a ser aproveitado na construção da subjetividade. A "mente corporificada" de Varela (1998) toma forma por meio do contato da criança, desde o nascimento, com esse ambiente, e vai se complexificando, incorporando as marcas de seu grupo e diferenciando-se por meio da apropriação de símbolos. Essa apropriação se dá a partir dos fenômenos transicionais e, posteriormente, pelo espaço potencial.

Devido à área intermediária, o esforço para manter os vínculos sociais que são constituintes da subjetividade não atrapalha a manifestação criatividade e da autenticidade da criança. A natureza do bom cuidado à criança consiste, sobretudo, em oferecer-lhe condições para elaborar sua especificidade. Para ser criativa, ela deve ser apta a vivenciar fenômenos transicionais, ou seja, poder construir um espaço potencial progressivamente, que a liga ao outro e que, em contra-partida, oferece-lhe um espaço para ser alguém integrado. Uma das raízes da criatividade é a possibilidade de pertencer a grupos sociais sem perder o sentido de continuidade do ser (Winnicott, 1975).

Na mesma sintonia, Moscovici (2000/2003) salientou que os afetos, a história pessoal e a posição do sujeito na comunidade onde vive estão engajados ao representar um objeto social. Primeiro porque para que um objeto seja alvo de um corpo de conhecimento relativamente organizado precisa ser relevante para o grupo referente e para o sujeito cognoscente. Além disso, a institucionalização do repertório representacional sobre determinado objeto só ocorre no ínterim das práticas cotidianas, nas exigências de reconhecimento que as práticas colocam. E cada sujeito reproduzirá as práticas que lhe cabem em seu contexto e de acordo com sua identidade social. É por isso que as representações sociais são transformáveis, e que novas representações são construídas a partir de lutas culturais, polêmicas intelectuais, oposições entre diferentes formas de pensar (Moscovici, 2000/2003), ao mesmo tempo em que certas representações permanecem hegemônicas por muito tempo.

Nesse ponto, percebemos a importância do diálogo entre diferentes posicionamentos ocorrendo a partir de um universo consensual. Esse universo consensual precisa estar presente, ainda que residualmente, antes que a comunicação criativa possa ocorrer. Isso quer dizer que o espaço de transitação do Eu e do Outro deve existir psiquicamente e socialmente para que a comunicação e a construção de sentidos comuns ocorram. O que será comunicado, para quem, e de que forma são aspectos diretamente influenciados pela existência de um espaço de mutualidade. Por isso, é a partir do compromisso psicossocial, por meio da comunicação, que sentimentos disfóricos suscitados por situações coletivas ansiógenas podem ser liberados e coletivizados, promovendo a emergência de representações sociais ou mudanças das já existentes (Jodelet, 2001). O equilíbrio sociocognitivo resultante da dinâmica das representações sociais é mantido pelo esforço de se ancorar o "novo", o "diferente", tornando-o familiar, de modo que não ameace tanto os vínculos e a estrutura social. $\mathrm{O}$ aspecto cognitivo está, portanto, articulado ao aspecto afetivo. 
A interlocução da teoria winnicottiana com a TRS já foi iniciada por Jovchelovitch (2000) em sua pesquisa sobre as representações sociais da esfera pública, e mais recentemente em seu livro "O contexto do saber" (2007/2008). A autora aprofunda a discussão sobre o uso do termo representação, trazendo um enfoque no desenvolvimento infantil, ancorando-se no conceito de espaço potencial. Ela observa que a atividade representacional está presente nos primórdios da constituição subjetiva, e que passa pelos fenômenos transicionais, devido à sua função simbólica. $\mathrm{O}$ símbolo e a representação criativa já estão presentes quando os primeiros afetos emergem na relação da criança com o mundo percebido. A relação entre atividade representacional e afetividade é retroativa e concomitante à constituição de um self integrado. Jovchelovitch (2007/2008) enfatiza que a representação simbólica é a atividade fundamental do espaço potencial, no qual também é constituída a mediação da relação com o outro e com a realidade. Essa mediação não se dá pela imposição e coerção, nem pela fantasia onipotente, mas é paradoxal, porque é a integração do self pelo reconhecimento da alteridade. A representação tem a função, portanto, de mediar esse reconhecimento.

Nesse processo dinâmico e constante de compreender a realidade na qual está inserido, o sujeito é movido por afetos, identificações e diferenciações, que são mecanismos do compromisso grupal. Assim, concluímos que processos afetivos estão ligados à necessidade de afastar a ameaça de desintegração do Eu e de conservar o grupo social com o qual se identifica. Para a sobrevivência desse sistema, ao longo das demandas de incorporação de novos e diferentes conteúdos, recorre-se às representações sociais. Se um problema social novo se coloca para um grupo, a necessidade de compreendê-lo e explicá-lo ocorre pela dinâmica das representações sociais, pelo recurso e readaptação ao repertório já legitimado. Os afetos podem ser identificados tanto na necessidade de incorporar o "novo" e superar a ameaça de desintegração quanto no retorno das representações às práticas diárias. Devido à complexidade do sistema, afetos são conduzidos, dirigidos a determinados objetos e atores sociais estereotipados ou categorizados por certas representações.

\section{Relação Entre Afetos e Representações Sociais}

Neste tópico, pretendemos aplicar a discussão teórica feita até aqui na análise dos resultados de uma pesquisa de representações sociais. A exploração do fenômeno de construção simbólica do espaço público num país como o Brasil, marcado por uma história ambivalente, em que se intercalaram períodos de ditadura e democracia, pareceunos muito rica para os objetivos desta pesquisa. Por isso, analisamos a função da afetividade na representação social da esfera pública no Brasil com base nos resultados da pesquisa de Jovchelovitch (2000. A aproximação da autora com os conceitos de Winnicott foi também um dos motivos para a escolha de seu trabalho.

De acordo Jovchelovitch (2000), a forma como os sujeitos se relacionam com o público, evocado na pesquisa pelos elementos ruas e vida política, indica como se interconectam seus espaços potenciais. Essa autora afirma, assim, que a comunicação e, consequentemente, o compartilhamento de representações ocorrem na intercessão entre espaços potenciais que transcendem a fronteira entre eu e não eu.

Jovchelovitch (2000) concluiu que a esfera pública no Brasil tem um caráter personalizado, ou "privatizado", que é organizado pela representação do "ser brasileiro" em seu núcleo. Há uma representação de um "ser brasileiro" generalizado, miscigenado e corrupto, que se impõe no espaço público, evocada para explicar os problemas públicos do país. Produz-se o seguinte paradoxo: o caráter da esfera pessoal é a explicação do caráter da esfera pública, o que podemos chamar de personalismo. Por outro lado, o personalismo também é composto pelo o que chamaremos de solidariedade e pela supervalorização dos laços pessoais e familiares. Esse paradoxo se torna em defesa contra a ameaça do "eu brasileiro" generalizado. Segundo a autora, a ética do coletivismo é evocada contra o perigo que o individualismo representa na esfera pública. Porém, esse coletivismo é caracterizado pela valorização das micro-relações, enquanto a vida política é associada à face "suja" da representação. Portanto, o "ser brasileiro" é um ser híbrido, ambíguo, e até mesmo indefinido, e por isso ameaça a identidade social dos brasileiros como cidadãos.

A função da afetividade para a construção dessas representações sobre a esfera pública no Brasil está no papel fundamental do medo e da solidariedade, ancorados nos mecanismos de constituição do self e de manutenção dos vínculos sociais. Como mencionado, a representação do "ser brasileiro" expressa uma identidade ambígua e paradoxal. No esforço por explicar a realidade social que os cerca, os sujeitos associam a esfera pública ao medo da imposição do "ser brasileiro", que, generalizado, arrisca contaminar e sufocar a identidade de cada um. Ou seja, o espaço público é de violência e opressão, porque ameaça a própria integração subjetiva. Em contrapartida, emerge uma defesa que se constitui na afirmação da solidariedade, que mantém o vínculo do sujeito com o social por meio de micro redes, expressas nos favorecimentos pessoais, inclusive no funcionamento de instituições públicas. É o famoso "jeitinho brasileiro" que escoa entre as regras sociais oficiais, marcando a ambiguidade da identidade brasileira. Sobre esse paradoxo podemos citar o ditado, lembrado por Jovchelovitch (2000, pág. 188): "para os amigos, tudo; para os inimigos, a lei".

Vimos que a relação entre o desenvolvimento emocional e o uso e construção de representações sociais é complexa e retroalimentar. Identificamos dois movimentos fundamentais dessa relação: (a) o sujeito emerge da relação com a sociedade, parte da indiferenciação para o reconhecimento do outro e de si, sendo o outro fundamental em sua constituição; (b) por outro lado, e também por isso, o sujeito está numa luta constante para se afirmar, construir-se enquanto indivíduo diferenciado, por meio da afirmação de sua potencialidade. Assim, os afetos perpassam processos que vão a duas direções: a da pertença social e a da potencialidade individual. As representações sociais são uma forma de conhecimento que viabiliza esse movimento, pois funcionam para manter o vínculo social enquanto também permitem apropriações individuais, ou melhor, negociações entre os sujeitos que as partilham. Moscovici (2000/2003) assinalou que esse processo de troca e composição de ideias comuns é necessário 
por responder às duplas exigências dos indivíduos e das coletividades. Podemos dizer que essas exigências têm forte carga afetiva, no nível consciente e no nível inconsciente.

Representar é a ação de tornar compreensível algo que se apresenta como objeto importante em seu meio cultural. Ser brasileiro constitui, assim, uma representação compartilhada que ajuda o sujeito a lidar com a realidade de pertencer a um país. Um jogo de negociações é produzido na interface da externalidade e interioridade - que retroalimenta sua própria experiência como brasileiro. Winnicott (1989/1994) referiuse ao medo do colapso do self como a ameaça que pode se impor em qualquer período da vida, já que a integração é sempre relativa. Jovchelovitch (2000) nos fala da tensão própria da subjetividade em ter que lidar com um mundo que, ainda que a preceda, está sempre aberto à sua criatividade. A manipulação de significados sociais está sempre nessa tensão, e esta se expressa em processos como as representações.

Estamos, assim, diante de um problema que se localiza entre teoria social e psicologia: o espaço potencial que se configura para um sujeito brasileiro, identificado com essa ambiguidade presente nas representações sociais do "ser brasileiro" e da esfera pública, pode ter seus limites esbarrando na vida política. A confiabilidade necessária para expressar sua autenticidade não existe em relação aos espaços públicos no Brasil, entre os participantes da pesquisa estudada. Ou seja, a cidadania não parece ser a via de manutenção do vínculo social do sujeito com o Brasil. O exercício da cidadania, que se baseia na relação com o Estado, representante de uma sociabilidade mais ampla, parece estar associado à ameaça de indiferenciação. Podemos concluir que uma função básica do medo e da solidariedade para a construção e apropriação dessas representações é a de manter o vínculo paradoxal dos brasileiros com seu país.

Concluímos, assim, que existem pontos de afinidade teórica consistentes entre a Teoria do Desenvolvimento Emocional de Winnicott e a Teoria das Representações Sociais de Moscovici, especialmente quanto à postura epistemológica dos autores. Embasando-nos numa abordagem transdisciplinar, foi possível não só aprofundar essa afinidade como também mostrar a implicação fundamental dos afetos para a construção e manutenção das representações sociais. Também percebemos que é possível analisar a presença de afetos em pesquisas empíricas de representações sociais já realizadas, o que nos leva a enfatizar ainda mais o desenvolvimento crescente da teoria.

\section{Referências}

Arruda, A. (2007, agosto). Meandros da teoria: a dimensão afetiva das representações sociais. Conferência proferida na $\mathrm{V}$ Jornada Internacional de Representações Sociais, Brasília.

Arruda, A. (2003). Viver é muito perigoso: A pesquisa em representações sociais no meio do rodamoinho. Em M. P. L. Coutinho, A. S. Lima, F. B. Oliveira \& M. L. Fortunato (Orgs.), Representações sociais: abordagem interdisciplinar (pp 11-31) João Pessoa: Editora UFPB.

Berger, P. L., \& Luckmannn, T. (2007). A construção social da realidade. (F. S. Fernandes, Trad.). Petrópolis: Vozes. (Trabalho original publicado em 1966)
Bezerra Jr, B., \& Ortega, F. (2007). Por que Winnicott hoje? Em B. Bezerra Jr. \& F. Ortega (Orgs.), Winnicott e seus interlocutores (pp. 7-12). Rio de Janeiro: Relume Dumará.

Brougère, G. (2004). Brinquedo e cultura. São Paulo: Cortez.

Chombart de Lauwe, M. J., \& Feuerhahn, N. (2001). A representação social na infância. Em D. Jodelet (Org.), As representações sociais (pp. 281-300) Rio de Janeiro: EDUERJ.

Corcuff, P. (2001) As novas sociologias: construções da realidade social. (V. Ribeiro, Trad.) Bauru: EDUSC. (Trabalho original publicado em 1995)

Durkheim, E. (1974). Individual and colective representations. Em E. Durkheim (Org.), Sociology and philosoph (ND). Nova Iorque: Free Press. (Trabalho original publicado em 1953)

Duveen, G. (2003). Introdução: o poder das ideias. Em S. Moscovici (Org.), Representações sociais: investigações em Psicologia Social (pp. 7-28) (P. A. Guareschi, Trad.). Rio de Janeiro: Vozes. (Trabalho original publicado em 2000)

Figueiredo, A. C. (1997). O que é feito da psicanálise. Em A. C. Fiqueiredo (Org.), Vastas confusões e atendimentos imperfeitos: a clínica psicanalítica no ambulatório público (pp.13-33). Rio de Janeiro: Relume Dumará.

Harré, R. (2001). Gramática e léxicos, vetores das representações sociais. Em D. Jodelet (Org.), As representações sociais (pp. 105122). Rio de Janeiro: EDUERJ.

Jodelet, D. (1988). Representação social: fenômenos, conceito e teoria. [Material para distribuição gratuita e circulação interna]. Rio de Janeiro: Fundação Getúlio Vargas.

Jodelet, D. (2001). Representações sociais: um domínio em expansão. Em D. Jodelet (Org.), As representações sociais (pp. 17-44). Rio de Janeiro: EDUERJ.

Jovchelovitch, S. (1994). Comment on M. Banchs "desconstruyendo uma desconstrucción ...". Papers on Social Representations - Textes sur les Représentations Sociales, 3, 1-4.

Jovchelovitch, S. (2000). Representações sociais e esfera pública: a construção simbólica dos espaços públicos no Brasil. Petrópolis: Vozes.

Jovchelovitch, S. (2001). Representações sociais: saberes sociais e polifasia cognitiva. Cadernos Cultura e Pesquisa (Blumenau), 2, 1-56.

Jovchelovitch, S. (2008). Os contextos do saber: representações, comunidade e cultura (P. A. Guareschi, Trad.). Rio de Janeiro: Vozes. (Trabalho original publicado em 2007)

Maisonneuve, J. A. (1977). Psicossociologia, ciência-charneira e ciência da interação. Em J. Maisonneuve (Org.), Introdução à psicossociologia (pp. 1-20). São Paulo: Nacional.

Morin, E. (1975). O enigma do homem: para uma nova antropologia (F. C. Ferro, Trad). Rio de Janeiro: Zahar. (Trabalho original publicado em 1973)

Morin, E. (1999). Por uma reforma do pensamento. Em A. Pena-Vega \& E. P. Nascimento (Orgs.), Pensar complexo: Edgar Morin e a crise da Modernidade (pp. 21-34). Rio de Janeiro: Garamond.

Moscovici, S. (1978). A representação social da psicanálise: resultados da pesquisa de opinião e análise teórica (A. Cabral, Trad.). Rio de Janeiro: Zahar. (Trabalho original publicado em 1966).

Moscovici, S. (2003). Representações sociais: investigações em Psicologia Social (P. A. Guareschi, Trad.). Rio de Janeiro: Vozes. (Trabalho original publicado em 2000) 
Pombo-de-Barros, C. F. (2007). Desenvolvimento emocional e Teoria das Representações Sociais: diálogo transdisciplinar. Monografia de Graduação, Universidade Federal do Rio de Janeiro, Rio de Janeiro.

Sancovschi, B. (2007). Sobre a noção de representação em S. Moscovici e F. Varela. Psicologia \& Sociedade, 19, 7-14.

Varela, F. J. (1998). A enação: uma alternativa à representação. Em F. J. Varela (Org.), Conhecer: as ciências cognitivas, tendências e perspectivas (pp. 71-98). Lisboa: Instituto Piaget.

Winnicott, D. W. (1975). O brincar e a realidade (J. O. A. Abreu \& V. Nobre, Trads.). Rio de Janeiro: Imago. (Trabalho original publicado em 1971)

Winnicott, D. W. (1988). Desenvolvimento emocional primitivo. Em D. W Winnicott (Org.), Textos selecionados: da pediatria à psicanálise (pp. 218-238) (J. Russo, Trad.). Rio de Janeiro: Francisco Alves. (Trabalho original publicado em 1945)

Winnicott, D. W. (1990). Natureza humana (B. L. Bogomoletz, Trad.). Rio de Janeiro: Imago. (Trabalho original publicado em 1988)
Winnicott, D. W. (1993). A família e o desenvolvimento individual (M. B. Cipola, Trad.). São Paulo: Martins Fontes. (Trabalho original publicado em 1965)

Winnicott, D. W. (1994). O medo do colapso (1963). Em C. Winnicott, R. Shepherd \& M. Davis (Orgs.), Explorações psicanalíticas (pp. 70-86) (J. O. A. Abreu, Trad.). Porto Alegre: Artes Médicas. (Trabalho original publicado em 1989)

Recebido em 22.11.2007

Primeira decisão editorial em 24.06.2008

Versão final em 03.12.2009

Aceito em 09.04.2010 